\title{
Pengembangan Konsep Brand Identity dan Visual System ITS yang Lebih Terintegrasi
}

\author{
Sayatman, Bambang Mardiono, dan Naufan Noordyanto \\ Departemen Desain Komunikasi Visual, Fakultas Desain Kreatif dan Bisnis Digital \\ Institut Teknologi Sepuluh Nopember, Surabaya, Indonesia \\ e-mail:sayatasik@gmail.com
}

\begin{abstract}
Abstrak—Brand Identity merupakan aspek yang sangat penting dalam sebuah entitas, antara lain sebagai tanda kepemilikan, jaminan kualitas, mencegah peniruan atau pembajakan. Selain sebagai ciri dan sarana identifikasi, brand identity juga dapat difungsikan sebagai alat promosi dan branding entitas tersebut. Institut Teknologi Sepuluh Nopember (ITS) sebagai sebuah entitas pendidikan tinggi teknologi di Indonesia sudah saatnya membangun konsep brand identity-nya secara lebih komprehensif, konsisten dan terintegrasi. Karena penggunaan brand identity secara konsisten dan terintegrasi sangat penting untuk mendukung brand image ITS dalam kontestasi lokal maupun global. Melalui pendekatan metode desain dan visual branding, penelitian ini bertujuan untuk mengembangkan konsep brand identity ITS secara lebih konsisten dan terintegrasi. Lingkup penelitian ini antara lain meliputi; studi eksisting terhadap penerapan system identitas visual yang ada, mengembangkan konsep desain dan pedoman penerapannya secara lebih terintegrasi pada atribut kebutuhan ITS. Hasil penelitian ini diharapkan dapat menjadi bahan pertimbangan kebijakan bagi ITS dalam penerapan visual identity system di ITS selanjutnya. Sehingga melalui penerapan brand identity yang teratur dan konsisten diharapkan dapat memberikan dampak dalam penguatan branding ITS menuju World Class University.
\end{abstract}

Kata Kunci-brand identity, identitas visual, branding ITS

Abstract - Brand Identity is a very important aspect in an entity, among others, as a sign of ownership, quality assurance, preventing imitation or piracy. Apart from being a feature and means of identification, brand identity can also function as a promotional and branding tool for the entity [1]. Institut Teknologi Sepuluh Nopember (ITS) as a higher technology education entity in Indonesia, it is time to build a more comprehensive and consistent brand identity concept. Because the consistent use of brand identity is very important to support ITS brand image in local and global contestation.

Through the design method approach and visual branding, this study aims to develop the ITS brand identity concept in a more consistent and integrated manner. The scope of this research includes; Existing studies on the application of existing visual identity systems, develop design concepts and guidelines for their implementation in a more integrated manner in formal attributes according to ITS needs. The results of the development of this design concept are expected to be material for policy considerations for ITS in the next application of the visual identity system at ITS. So that through the regular and consistent application of brand identity, it is hoped that it can have an impact in strengthening ITS branding towards World Class University.

Keywords - brand Identity, Visual Identity, ITS Branding.

\section{PENDAHULUAN}

Brand Identity atau juga dikenal dengan istilah identitas visual (visual identity) merupakan sekumpulan tanda yang secara grafis mengandung ciri khas tertentu yang mencitrakan sebuah entitas yang diwakilinya. Entitas tersebut dapat berupa institusi, lembaga, organisasi atau bahkan personal [1] dan [2]. Identitas visual merupakan aset yang sangat penting bagi sebuah entitas, antara lain sebagai tanda kepemilikan, jaminan kualitas, mencegah peniruan atau pembajakan. Selain menjadi bagian dari properti legal sebuah entitas, identitas visual juga berfungsi sebagai sarana identifikasi, diferensiasi, komunikasi, marketing dan sarana branding.

Institut Teknologi Sepuluh Nopember (ITS) sebagai sebuah entitas pendidikan tinggi teknologi terkemuka di Indonesia sudah selayaknya mengimplementasikan system identitas visual yang lebih terintegrasi sebagai bagian dari upaya penguatan branding institut dalam mencapai visi misinya menjadi perguruan tinggi bereputasi internasional. Melalui penerapan system identitas yang terintegrasi maka diharapkan dapat merefleksikan budaya dan jati diri institusi ITS.

Secara mendasar, sebagaimana diatur dalam statutanya, ITS sudah memiliki atribut identitas visual formal, termasuk di dalamnya logo, lambang, bendera, pataka, toga, dan sebagainya [3]. Namun demikian identitas yang tercantum dalam statuta institut lebih bersifat legal formal dan terbatas, belum dikembangkan lebih detail hingga menjadi sistem identitas visual yang konsisten dan komprehensif sesuai kebutuhan institut. Padahal identitas visual adalah asset berharga ITS yang bisa dikelola dan dioptimalkan menjadi sarana identifikasi, diferensiasi, bahkan sebagai sarana komunikasi pemasaran dan membangun brand image ITS.

Identitas visual bukan hanya logo atau lambang saja, lebih luas dari itu merupakan kombinasi dari logo dan elemen grafis lainnya, misalnya; tipografi (letter mark), gambar (picture mark), warna identitas (color identity), tata letak (basic layout), atau hasil kombinasinya. Perpaduan inilah yang kemudian jika dikelola dengan baik akan membentuk visual identity system yang terintegrasi sekaligus menguatkan branding entitas institusi yang diwakilinya.

Ruang lingkup penelitian ini antara lain meliputi; audit terhadap penerpan system identitas visual yang ada (eksisting), merancang konsep desain system identitas visual yang terintegrasi dan mengembangan pedoman penerapannya pada atribut media sesuai kebutuhan ITS. Fokus luaran penelitian ini antara lain berupa brand guideline sebagai pedoman penggunaan brand dan identitas visual di lingkungan ITS, khususnya untuk kebutuhan media administrasi kantor (office stationery), perangkat promosi 
(promotion tools), papan petunjuk (sign system), seragam (uniform), kendaraan operasional (vehicle) benda souvenir (merchandise) lainnya. Hasil penelitian ini diharapkan dapat menjadi bahan rekomendasi kebijakan pimpinan dalam penerapan system identitas visual di ITS. Selanjutnya dapat dikembangkan pada sub-sub entitas yang ada di dalamnya secara hirarkis, dari tingkat rektorat, fakultas hingga departemen.

Berdasarkan pengamatan di lapangan (Gambar 1), sering ditemukan inkonsistensi dan ketidakseragaman pada beberapa implementasi sistem identitas visual di lingkungan ITS. Bahkan penggunaan logo maupun lambang formal sekalipun seringkali melenceng dari aturan identitas visual yang sudah ditentukan, baik dari sisi bentuk, warna, tata letak maupun perlakuan visualnya. Hipotesa sementara, antara lain karena belum adanya panduan yang komprehensif tentang penggunaan identitas dalam ragam media yang dimkasud. Di sisi lain adanya kebijakan penggunaan 2 (dua) identitas visual yakni logo dan lambang kadang-kadang menimbulkan ambiguitas identitas visual di mata publik, dan sebagian pengguna masih merasa bingung dalam penerapannya. Untuk itu perlu dilakukan penelitian untuk mengaudit implementasi system identitas visual di lingkungan ITS. Karena jika dibiarkan berlarut-larut akan berpotensi mereduksi efektifitas kerja identitas itu sendiri.

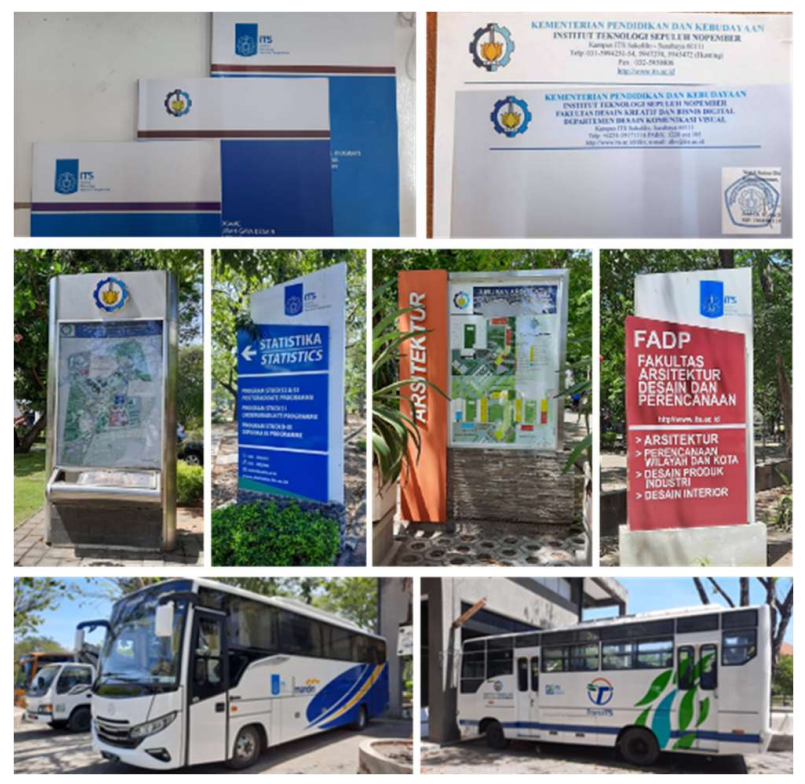

Gambar 1. Eksisting penerapan Visual Identity di ITS.

Secara teoritis, identitas tunggal lebih mudah diidentifikasi dibanding dengan multi identitas visual untuk satu entitas. Karena jika dalam dalam satu entitas terdapat dua identitas, maka cenderung menimbulkan ambiguitas atau keraguan dalam identifikasinya. Untuk itu selanjutnya perlu dicari solusi konsep dan pedoman penerapan visual identity system yang lebih konsisten dan terintegrasi.

Penelitian ini menjadi penting sebagai bahan evaluasi diri bagi ITS bahwa pengembangan system identitas visual memiliki kontribusi dalam mendukung citra ITS sebagai perguruan tinggi yang profesional. Penelitian ini diharapkan dapat bermanfaat bagi pengembangan konsep visual identity system di ITS ke depan secara lebih terintegrasi. Sehingga selain memenuhi fungsinya sebagai ciri atau penanda visual, juga dapat memberi dampak dalam upaya memperkuat branding ITS menuju World Class University.

\section{METODE}

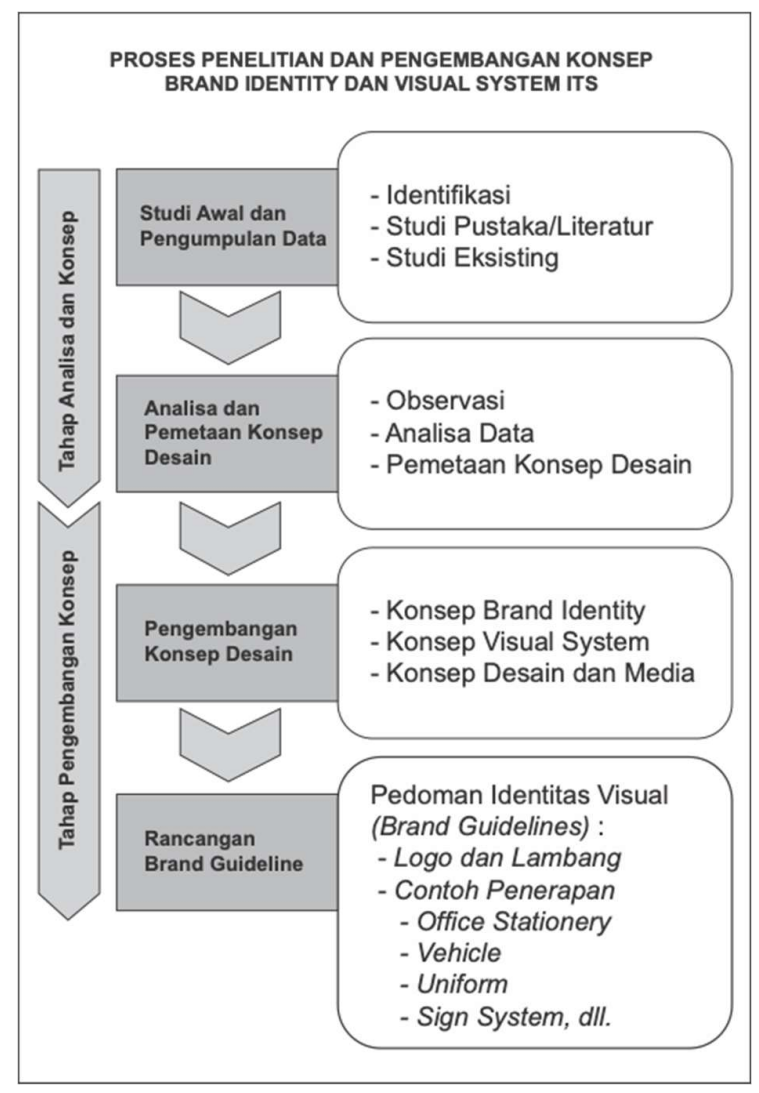

Gambar 2. Proses pengembangan konsep Brand Identity ITS.

Dalam penelitian ini pendekatan analisis dilakukan melalui studi pendahuluan, observasi, studi eksisting dan iteratur mengenai brand identity. Selanjutnya pada tahap pengembangan konsep desain dilakukan eksperimen dengan pendekatan metode desain visual branding.

Ada 3 (tiga) tahapan pendekatan dalam pengembangan konsep brand identity ITS ini, yaitu:

1. Tahap Studi awal dan pengumpulan data, meliputi identifikasi dan studi eksisting.

2. Tahap analisa dan pemetaan konsep, meliputi observasi, analisa dan pemetaan konsep.

3. Tahap Pengembangan konsep, meliputi konsep identitas, sistem visual dan konsep desain.

Gambar 2 menunjukan bagaimana langkah proses penelitian dan pengembangan konsep brand identitas dan sistem visual di ITS.

\section{HASIL DAN PEMBAHASAN}

\section{Konsep Branding}

Branding adalah proses yang berkesinambungan untuk membangun kesadaran merek dan memperluas loyalitas pelanggan terhadap merek. Branding juga bisa diartikan bagaimana memanfaatkan setiap peluang untuk menyampaikan pesan tentang mengapa seseorang harus 
memilih sebuah brand tertentu dibanding brand yang lain [4]. Mengapa sebuah perusahaan memanfaatkan branding, karena branding merupakan investasi perusahaan untuk berkompetisi, memimpin sekaligus menjadi alat pemasaran yang terbaik untuk memenangkan hati pelanggan. Identitas merek mendorong pengakuan, memperkuat diferensiasi, dan membuat ide-ide besar dan makna dapat diakses.

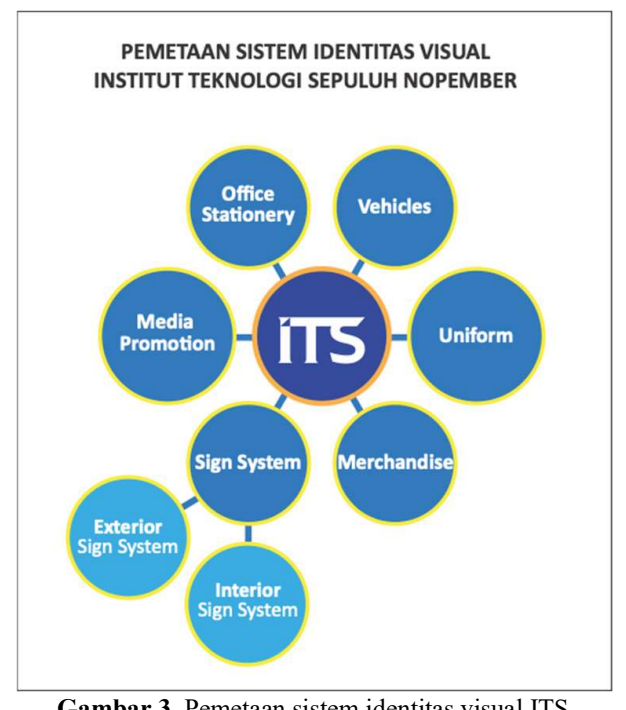

Gambar 3. Pemetaan sistem identitas visual ITS

\section{Strategi Branding ITS}

Strategi Branding ITS sebaiknya dibangun di atas visi yang selaras dengan strategi bisnis dan nilai-nilai dan budaya kerja ITS yang mencerminkan sebuah perguruan tinggi yang unggul dalam memberi layanan pendidikan sesuai kebutuhan masyarakat. Visi ITS sebagaimana tertuang dalam statuta yaitu "Menjadi Perguruan Tinggi berkelas dunia yang berkotribusi pada kemandirian bangsa serta menjadi rujukan dalam pendidikan, penelitian dan pengabdian masyarakat serta pengembangan inovasi terutama yang menunjang industri dan kelautan" [5]. Strategi brand ini selanjutnya mendefinisikan positioning, diferensiasi, keunggulan kompetitif, dan preposisi unik ITS di benak masyarakat dan semua pemangku kepentingan (stakeholder),

Sebagai sebuah institusi pendidikan tinggi, ITS juga dapat diibaratkan sebuah perusahaan (corporate) yang memiliki core bisnis, budaya kerja dan brand. Pengertian brand memiliki makna yang lebih dalam dari sekedar logo. Jika logo atau lambang ITS adalah sebuah wujud yang bisa dilihat secara visual, maka brand mencakup keseluruhan, baik yang berupa fisik dan non fisik. Dengan kata lain brand adalah rangkuman nilai-nilai esensial dari suatu entitas. Jika diibaratkan seorang manusia, logo adalah wajah seseorang, identitas adalah penampilan fisik, perilaku dan cara berkomunikasi, maka brand adalah keseluruhan jiwa raga manusia itu termasuk logo didalamnya [6].

\section{Corporate Identity ITS}

Dalam sebuah entitas perusahaan (corporate), identitas perusahaan dikenal dengan istilah corporate identity dan biasanya meliputi identitas verbal dan identitas visual. Tujuan dari corporate identity secara umum adalah sebagai ciri agar entitas tersebut dikenal oleh semua pihak. Sebagai bagian dari identitas corporate, logo merupakan wajah dan identitas yang sangat penting, karena fungsi logo bukan hanya bersifat mengidentifikasi, namun juga memberikan kesan atau persepsi secara tidak langsung tentang seluk beluk filosofi perusahaan [7]. Kesan inilah yang kemudian akan dibangun menjadi sebuah identitas korporat (corporate identity) melalui simbolisasi visual. Sehingga dalam hal ini identitas visual selain digunakan sebagai alat identifikasi, juga sebagai sarana untuk memahami makna filosofis perusahaan.

Tabel 1. Pemetaan media aplikasi identitas visual.

\begin{tabular}{|c|c|c|c|}
\hline No & Jenis Media & Uraian & Contoh Media \\
\hline 1 & $\begin{array}{l}\text { Office } \\
\text { Stationery }\end{array}$ & $\begin{array}{l}\text { Penerapan system identitas } \\
\text { visual pada media-media } \\
\text { yang berhubungan dengan } \\
\text { kebutuhan administrasi } \\
\text { akademik dan perkantoran } \\
\text { sehari-hari }\end{array}$ & $\begin{array}{l}\text { Kop Surat } \\
\text { Amplop } \\
\text { Stopmap } \\
\text { Stampel } \\
\text { Kartu Nama } \\
\text { Name Tag, dll. }\end{array}$ \\
\hline 2 & Vehicles & $\begin{array}{l}\text { Penerapan system } \\
\text { identitas visual pada } \\
\text { kendaraan opearsioanal } \\
\text { untuk kebutuhan mobilitas } \\
\text { di dalam lingkungan ITS } \\
\text { maupun di luar kampus }\end{array}$ & $\begin{array}{l}\text { Kendaraan Patroli } \\
\text { SKK } \\
\text { Bis Kampus } \\
\text { Kendaraan Sarpras } \\
\text { Kebersihan dan } \\
\text { pemeliharaan taman } \\
\text { iCar, dll. }\end{array}$ \\
\hline 3 & Uniform & $\begin{array}{l}\text { Penerapan system } \\
\text { identitas visual pada } \\
\text { seragam civitas akademika } \\
\text { di lingkungan ITS. }\end{array}$ & $\begin{array}{l}\text { Seragam batik ITS, } \\
\text { Seragam Satuan } \\
\text { Keamanan Kampus } \\
\text { (SKK) } \\
\text { Jas almamater, } \\
\text { Toga } \\
\text { Tim Olah Raga, dll. }\end{array}$ \\
\hline 4 & $\begin{array}{l}\text { Promotion } \\
\text { Media }\end{array}$ & $\begin{array}{l}\text { Penerapan system } \\
\text { identitas pada media- } \\
\text { media promosi atau media } \\
\text { publikasi lain yang } \\
\text { digunakan secara official. }\end{array}$ & $\begin{array}{l}\text { Website } \\
\text { Majalah ITS Point } \\
\text { Banner } \\
\text { Spanduk } \\
\text { Brosur } \\
\text { Poster } \\
\text { Katalog, dll. }\end{array}$ \\
\hline 5 & Sign System & $\begin{array}{l}\text { Penerapan system } \\
\text { identitas pada papan nama } \\
\text { atau penunjuk arah. } \\
\text { Tujuannya sebagai } \\
\text { penanda pada interior, } \\
\text { eksterior dan lingkungan } \\
\text { kampus. }\end{array}$ & $\begin{array}{l}\text { Orientation Map } \\
\text { Sign System } \\
\text { penunjuk } \\
\text { Nama gedung/ruang }\end{array}$ \\
\hline 6 & Merchandise & $\begin{array}{l}\text { Merupakan benda-benda } \\
\text { souvenir/gimmick yang } \\
\text { bertujuan untuk } \\
\text { membantu mengingatkan } \\
\text { pada entitas ITS. }\end{array}$ & $\begin{array}{l}\text { T Shirt } \\
\text { Gantungan Kunci } \\
\text { Maskot } \\
\text { Kemasan, dll. }\end{array}$ \\
\hline
\end{tabular}

Identitas Visual merupakan kombinasi dari logo dan system visual (typography, colour, imagery) yang dibuat secara terpadu untuk menyampaikan pesan dari sebuah perusahaan, orang, benda atau bahkan ide [8], [9], dan [10]. Elemen utama identitas visual yang umum digunakan antara lain; tulisan (lettermark), gambar logo (picture mark), warna (color identity), tata letak (basic layout), principal letter dan maskot atau hasil kombinasinya.

\section{Pemetaan Sistem Identitas Visual ITS (Visual Identity System ITS)}

Logo sebagai bagian dari identitas visual pada dasarnya merupakan modal awal dalam proses pembentukan visual branding. Segala penerapan sistem visual (visual system) dalam berbagai media, termasuk media publikasi dan promosi di ITS sebaiknya selalu disertai identitas visual yang konsisten, sehingga khalayak menjadi lebih akrab dengan ciri entitas ITS.

Untuk membangun sistem identitas visual ITS yang terintegrasi maka perlu dirancang sebuah sitem grafis yang fungsinya menjadi elemen identitas sekaligus untuk mengikat 
system identitas visual secara lebih terintegrasi dalam berbagai media. Sistem grafis sebagai pendukung identitas visual ITS dapat dikembangkan dari unsur-unsur visual logo atau lambang utama seperti, warna, gambar, bentuk huruf dan tata letak.

Elemen-elemen visual tersebut kemudian didesain secara artistik dan harmonis sehingga dapat menjadi pengikat keseluruhan desain dalam sebuah system desain (design system). Perpaduan inilah yang kemudian akan membentuk visual identity system.

Gambar 3 menunjukan pemetaan identitas visual di lingkungan ITS yang akan diterapkan pada berbagai media dan atribut yang sering dibutuhkan ITS. Beberapa contoh aplikasi identitas yang dibutuhkan antara lain kebutuhan administrasi kantor, kendaraan operasional kampus, seragam, media promosi kampus, sign system (eksterior dan interior) dan merchandise.

Tabel 1 menunjukan ragam media aplikasi yang memungkinkan identitas visual diterapkan pada berbagai jenis dan contoh media yang sering dibutuhkan di lingkungan ITS.

\section{WARNA PRIMER}

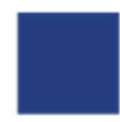

$\min _{\sin }$ coven

$\log ^{208}$

Curk
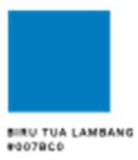

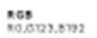

curk
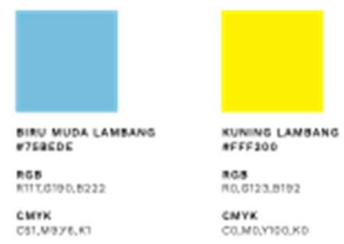

WARNA SEKUNDER

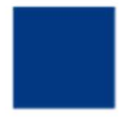

ginu rua

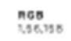

curve

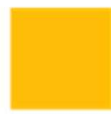

Kunisa rua

nes

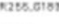

cums
cavasmonso

WARNA FAKULTAS
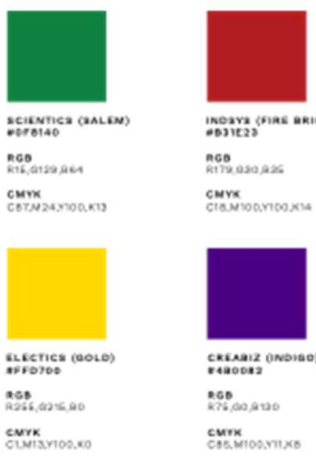

inears soras akick

ncos

carys

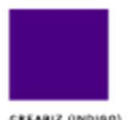

Cxinaiz andiao)
-taoosa

$\cos _{000000}$

curx
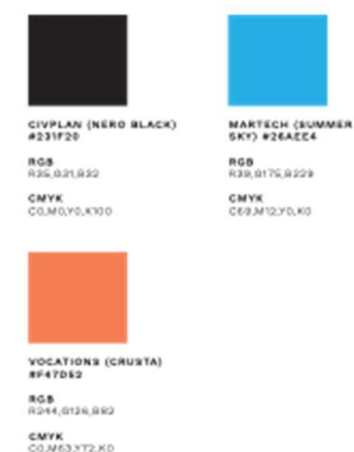

Gambar 4. Warna Identitas (Colour Identity) ITS.

\section{Warna Identitas}

Penggunaan warna pada Institut Teknologi Sepuluh Nopember mempunyai 4 warna primer dan 2 warna sekunder. Penggunaan warna primer digunakan untuk seluruh kebutuhan grafis sedangkan warna sekunder hanya dipakai untuk keperluan website dan media sosial.

Dalam implementasinya, warna fakultas diciptakan sebagai identitas tiap fakultas yang berada di Institut Teknologi Sepuluh Nopember. Warna-warna ini hanya boleh dipergunakan sebagai aksen ataupun penanda identitas fakultas saja (Gambar 4).

\section{Typography}

Dalam penggunaan Tipografi, terdapat 2 font yang digunakan yaitu Font Friz Quadrata Std dan Work Sans Family. Friz Quadrata Std merupakan signature font yang dipakai pada wordmark lambang dan logo ITS sedangkan Work Sans family dipakai untuk keperluan body text dan kepentingan penulisan lainnya.

\section{Friz Quadrata Std}

abcdefghijklmnopqrstuvwxyz ABCDEFGHIJKLMNOPQRSTUVWXYZ

1234567890

!@\#\$\%^\&*()_+\{\}"<>?

\section{Work Sans Family}

abcdefghijklmnopqrstuvwxyz

ABCDEFGHIJKLMNOPQRSTUVWXYZ

1234567890

!@\#\$\%^\&*()_+\{\}"<>?

Gambar 5. Typografi dan Font.

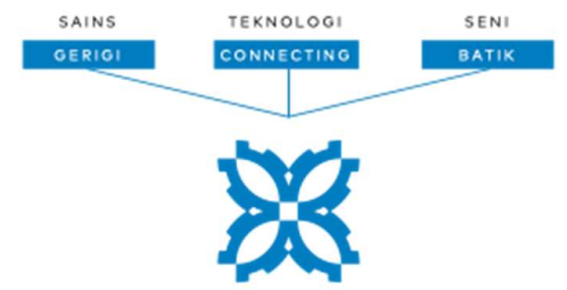

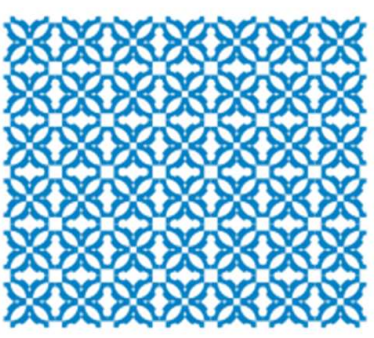

Key Graphic Filled version.

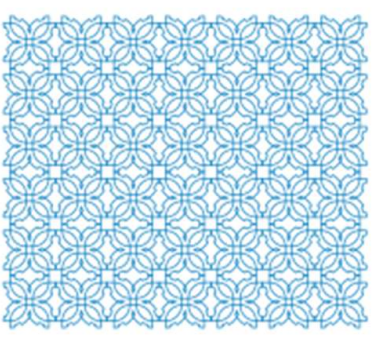

Key Graphic Outline version.
Gambar 6. Konsep Supergraphic ITS

\section{Supergraphic}

Supergraphic merupakan elemen visual yang menjadi pendukung identitas. Biasanya terdiri dari elemen warna, bentuk atau kombinasinya. Fungsi supergrafis selain memperkuat identitas visual logo sekaligus menjadi elemen estetik dan pengikat system grafis di setiap medianya. Jika penggunaan logo cenderung monoton dan konstan, maka key grafis relatif lebih fleksibel dalam implementasinya, sehingga dapat dikreasikan sedemikain rupa hingga menjadi system identitas yang estestik. 
Supergraphic ITS yang dirancang merupakan hasil dari perpaduan antara Elemen Gerigi, Konsep Connecting serta bentuk akhir yang berbentuk batik/pattern. Hal ini merupakan sebuah representasi dari 3 elemen penting di ITS yakni Sains, Teknologi dan Seni. Penggunaan grafis ini dapat dimanfaatkan untuk berbagai kepentingan grafis dalam implementasi desain (Gambar 6).

\section{Stationery Set dan administrasi perkantoran}

Kegiatan surat menyurat dan administrasi perkantoran adalah salah satu kebutuhan yang paling sering digunakan dalam aktifitas sehari-hari, baik yang berhubungan dengan pihak internal maupun dengan pihak di luar ITS. Kebutuhan media seperti kop surat, amplop, stempel, kartu nama, name tag adalah media yang rutin digunakan.

Berikut ini adalah contoh konsep implementasi pada media stationery yang sering diperlukan. Aplikasi disamping menggunakan format lambang dengan wordmark (Gambar 7).

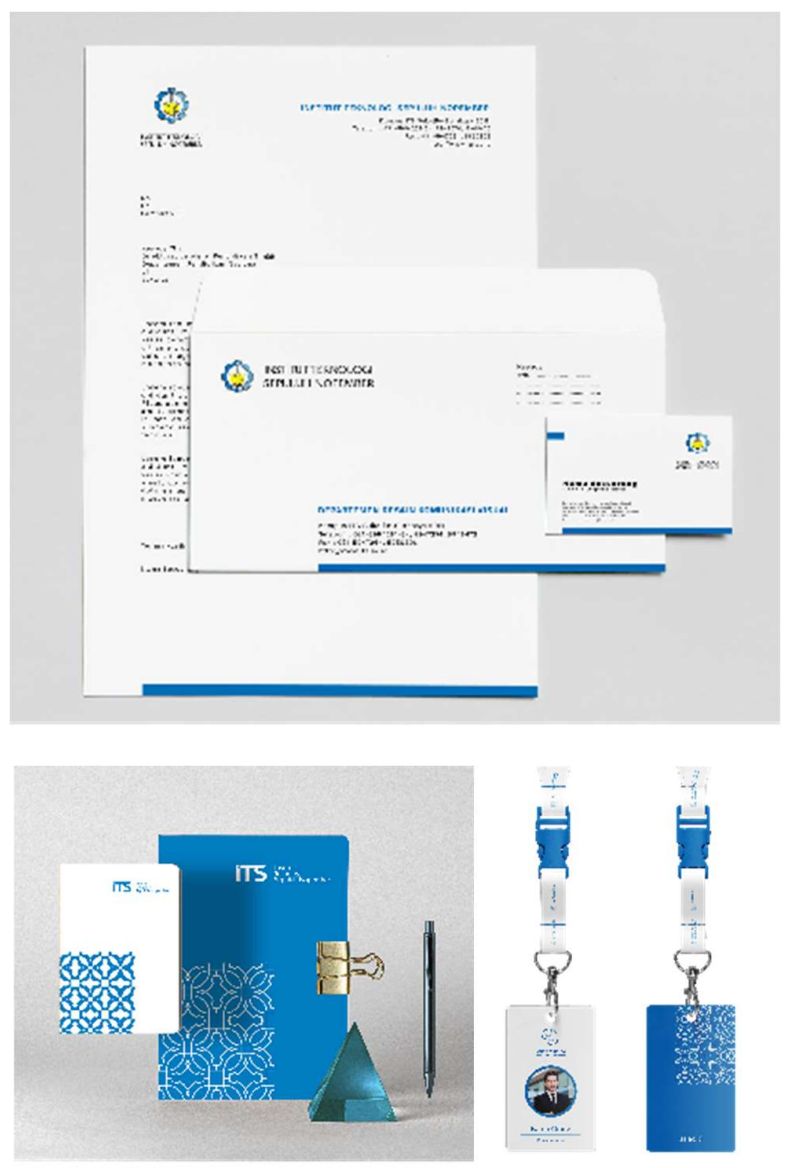

Gambar 7. Alternatif Desain Stationery Set.

\section{Kendaraan operasional kampus}

Kendaraan operasional adalah salah satu properti pendukung mobilitas dan sarana angkutan di dalam lingkungan kampus maupun di luar kampus ITS. Karena sifatnya yang mobile, maka kendaraan operasional ini mudah dilihat oleh khalayak. Keberadaannya yang sering beredar dan dilihat publik tersebut berpotensi menjadi sarana promosi dan branding identitas ITS, sehingga kendaraan operasional kampus ini potensial untuk digarap branding identitasnya secara lebih komprehensif (Gambar 8).
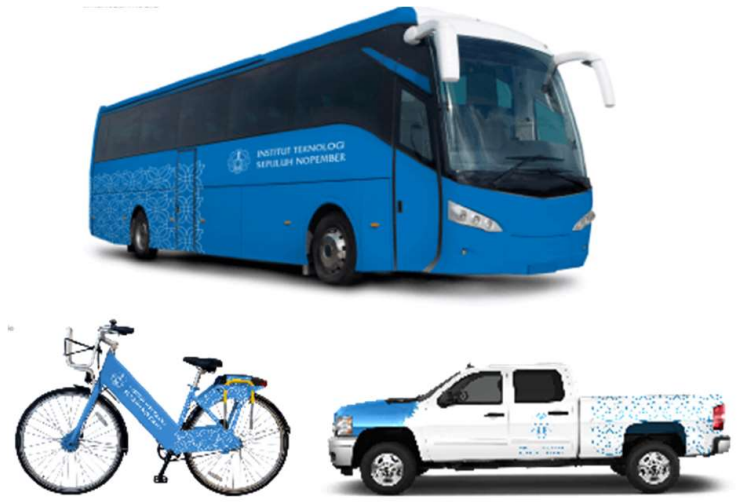

Gambar 8. Alternatif Desain Identitas pada kendaraan operasional kampus.
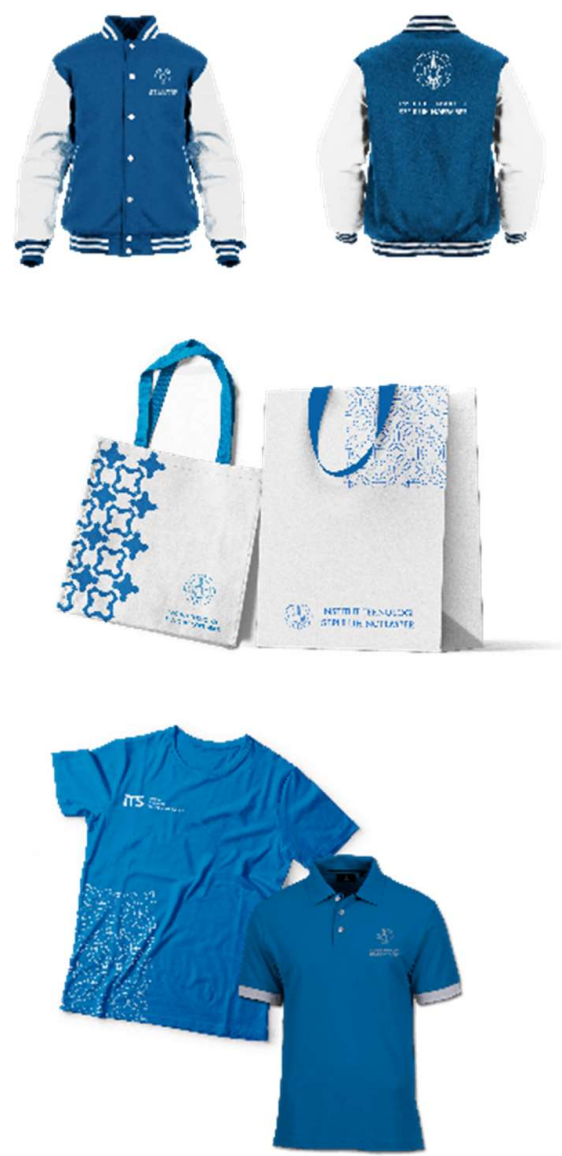

Gambar 9. Alternatif Desain Merchandise

\section{Merchandise}

Merchandise adalah benda yang secara khusus diproduksi untuk keperluan oleh-oleh, tanda mata atau souvenir bagi konsumen atau pelanggan. Merchandise juga dapat menjadi alternatif promosi untuk membangun kesadaran akan brand tanpa memaksa konsumen menerima pesan yang disampaikan. Karakteristik merchandise yang memiliki sentuhan personal (personal touch) membawa kedekatan tersendiri dengan konsumennya (Gambar 9).

Banyak bentuk dan jenis merchandise yang potensial untuk digarap sebagai sarana remainder dan branding ITS. Benda pajang dan benda pakai berukuran kecil, benda 
fashion, kemasan, dan benda souvenir lainnya, bahkan dapat dikembangkan terus pada media-media baru yang lebih kreatif, sehingga dapat dikelola sebagai sarana penguatan brand indentity ITS.

\section{Website ITS}

Website di era informasi internet seperti saat ini bisa dikatakan media utama untuk mengakses informasi. Keberadaan website ITS sebagai jendela informasi ITS sangat membantu dalam menyampaikan informasi terkini mengenai segala sesuatu tentang ITS. Saat ini website ITS sudah mengalami perubahan dan pembenahan yang cukup signifikan baik terutama dari segi konten, bahkan pernah meraih penghargaan terbaik ke 2 sebagai konten terlengkap. Secara visual hal ini juga menjadi memberikan kesan tampilan yang lebih terintegrasi dan tampak terorganisasi dengan baik. Informasi yang disajikan dalam dual bahasa (Indonesia dan English) juga memberi akses yang lebih luas kepada masyarakat di seluruh dunia untuk lebih mengenal ITS melalui situs web tersebut (Gambar 10).

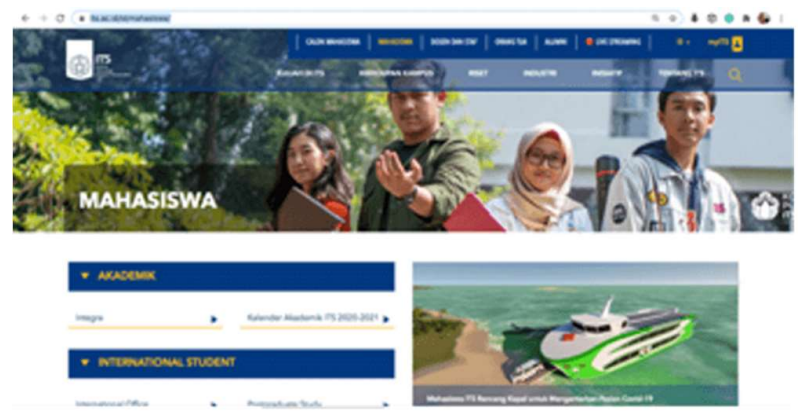

Gambar 10. Contoh tampilan antarmuka Website ITS

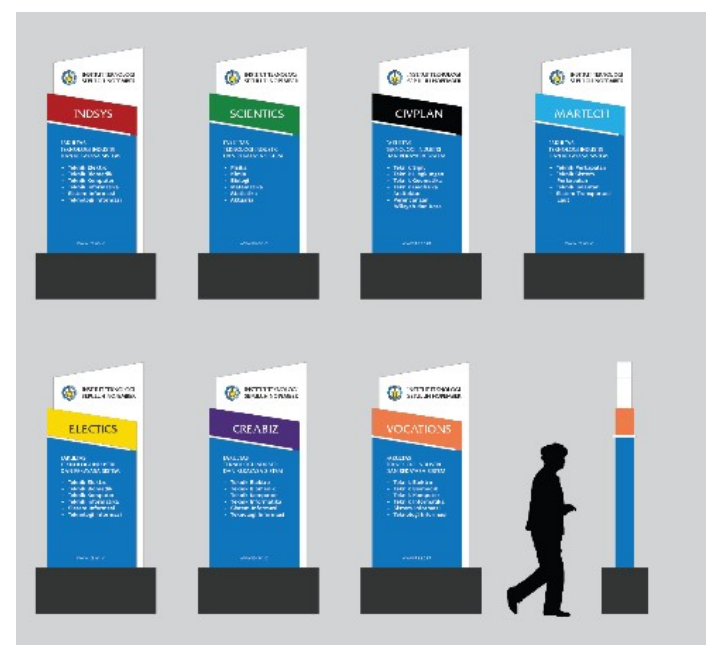

Gambar 11. Alternatif Desain Signage Fakultas dan Departemen

\section{Papan penanda (Signage)}

Jika dikelompokan ada beberapa jenis sign system, antara lain: 1) Identification sign, yaitu petunjuk yang sifatnya menginformasikan atau mengidentifikasi suatu ruangan, gedung atau area tertentu. 2) Information sign, yaitu penunjuk yang menginformasikan suatu fitur fasilitas suatu gedung atau area, bisa berupa denah atau peta yang dapat membantu pengunjung mengenal area ITS dan dimana mereka berada.3) Directional sign, yaitu petunjuk yang menginformasikan rute, arah dari suatu area/ruang tertentu yang ingin dituju (Gambar 11).

\section{KESIMPULAN}

Penggunaan identitas visual yang konsisten cenderung lebih memudahkan publik dalam mengidentifikasi dan mengenali ciri entitas dibanding dengan multi identitas. Kebijakan penggunaan 2 (dua) identitas visual seperti logo dan lambang secara bersamaan memang berpotensi menimbulkan ambiguitas persepsi identitas visual di mata publik. Jika dibiarkan berlarut-larut akan berpotensi mereduksi efektifitas kerja identitas itu sendiri. Sehingga diperlukan aturan yang lebih jelas aturan penggunaan keduanya.

Diperlukan brand guideline yang dapat dijadikan panduan penggunaan Identitas Visual di ITS. Brand Guideline ini juga sekaligus sebagai dokumen kebijakan dalam penerapan Identitas Visual di lingkungan ITS. Selanjutnya panduan tersebut diharapkan dapat menjadi acuan pengimplementasian visual identity system dalam berbagai media yang dibutuhkan di ITS, sehingga tercipta sebuah sistem grafis yang lebih konsisten dan terintegrasi. Melalui penerapan sistem identitas yang konsisten dan terintegrasi akan sangat membantu dalam mendukung pembangunan citra (image) ITS.

\section{UCAPAN TERIMA KASIH}

Terima kasih disampaikan kepada Insitut Teknologi Sepuluh Nopember yang telah mendanai penelitian ini sekaligus menjadi objek penelitian. Direktorat Penelitian dan Pengabdian Masyarakat (DRPM) ITS sebagai pengelola program Penelitian. Pusat Unggulan Industri (PUI) Desain Kreatif ITS yang sudah memberi kesempatan kepada kami tim peneliti brand untuk mengembangkan penelitian ini sebagai bagian penelitian pendukung kebijakan di ITS.

\section{DAFTAR PUSTAKA}

[1] Alina Wheeler. 2018. Designing Brand Identity. Published John Wiley and Sons Inc., Hoboken New Jersey.

[2] Morioka Adams. 2004. Logo Design Workbook- A hands on Guide to Creating Logos.USA: Rockport Publishers, inc.

[3] Statuta Institut Teknologi Sepuluh Nopember, 2011.

[4] Aaeker, David A. Building Strong Brands, The Free Press, New York.1996.

[5] Buku Saku-World Class University Rangking Institut Teknologi Sepuluh Nopember (ITS) Surabaya.

[6] Rustan, Surianto, S.Sn.2009. Mendesain Logo. Jakarta: PT Gramedia Pustaka Utama.

[7] Balmer, John, M.T \& Edmund R. Gray." Corporate Identity and Corporate Communications: Creating a strategic advantage," Corporate Communication. 1998

[8] Wiryawan, Mendiola B. 2008. Kamus Brand A-Z. Jakarta: Red \& White Publishing.

[9] Supriyono, R. (2010). Desain Komunikasi Visual. Teori dan Aplikasi. Yogyakarta: Andi.

[10] Kautsar, M. A., \& Indrayana, D. (2012). Perancangan Environmental Graphic Design Kebun Binatang Surabaya dengan Konsep Uniquely Playful. Jurnal Sains dan Seni ITS, 1(1), F66-F71. 